\title{
latrogenic obstruction of the aorta - a sequence of delayed, fatal complications after 'off-label' interventional persistent ductus arteriosus closure
}

\author{
Ireneusz Haponiuk ${ }^{1,2}$, Konrad Paczkowski², Maciej Chojnicki², Radosław Jaworski² \\ ${ }^{1}$ Department of Physiotherapy, Faculty of Rehabilitation and Kinesiology, Gdansk University of Physical Education and Sport, Gdansk, \\ Poland \\ 2Department of Pediatric Cardiac Surgery, Mikolaj Kopernik Hospital, Gdansk, Poland
}

Videosurgery Miniinv 2016; 11 (1): 44-48 DOI: $10.5114 /$ wiitm.2016.57620

\begin{abstract}
A 10-month-old girl was admitted to the Intensive Care Unit with the symptoms of critical cardiac decompensation. In the $3^{\text {rd }}$ month of life, $3 \mathrm{~kg} \mathrm{bw}$, she underwent an interventional persistent ductus arteriosus (PDA) closure in a high-reference pediatric cardiology center. Echocardiography performed on admission showed myocardial injury, with poor contractility, mild pulmonary hypertension and severe stenosis of the isthmus of aorta. The girl was urgently referred for surgical removal with the use of extracorporeal circulation (ECC) and deep hypothermia circulatory arrest (DHCA) technique. In the $4^{\text {th }}$ postoperative day (POD), she developed cardiovascular decompensation and died in the $7^{\text {th }} P O D$ due to circulatory arrest in the mechanism of refractory ventricular fibrillation. In autopsy there were found microscopic signs of apoptosis in parenchymal organs below iatrogenic 'coarctation', typical for chronic ischemia. In the segments proximal to iatrogenic aortic stenosis there were evident vascular changes characteristic for chronic severe arterial hypertension.
\end{abstract}

Key words: congenital heart defect, interventional cardiology, pediatric cardiac surgery, complications.

\section{Introduction}

Percutaneous closure of persistent ductus arteriosus (PDA) is a well-established clinical routine in contemporary medicine. There are several surgical techniques as well as interventional treatment strategies available for cardiologists and cardiac surgeons [1]. Despite preferred standards and the individually chosen way of treatment, the results are encouraging, while the procedures are regarded as easy and uncomplicated in the majority of cases reported [2]. Thus the most important question is proper qualification for various types of interventions with regard to precise inclusion criteria as well as individual patient's needs.
The first described percutaneous PDA closure comes from 1967 [3], although with the introduction of intravascular coils and vascular plugs, since the late nineties percutaneous PDA closure has become a regular clinical practice.

The intervention is usually followed by recommended, scheduled clinical controls, which are of great importance to assess both the condition of the patient and the final outcome of the procedure. Nevertheless, every interventional PDA closure could result in some complications that appear not directly after the procedure, or delayed symptoms of suboptimal results are observed in short-term follow-up. The problems are much more important in pediatric

\section{Address for correspondence}

Ireneusz Haponiuk MD, PhD, Department of Pediatric Cardiac Surgery, Mikołaj Kopernik Hospital, 1-6 Nowe Ogrody St, 80-803 Gdansk,

Poland, phone/fax: +48 5876404 90, e-mail: kardiochirurgia@wss.gda.pl 
patients, in whom the device mismatch phenomenon could cause delayed fatal consequences.

\section{Case report}

A 10-month-old girl (weight $5.43 \mathrm{~kg}$ ) suffering from Down syndrome and hypothyroidism was admitted in an emergency setting to the Intensive Care Unit with the symptoms of critical cardiac decompensation. The girl was transferred from another high-reference pediatric cardiology center with the diagnosis of critically narrowed aortic coarctation. In her medical history in the $3^{\text {rd }}$ month of life, weight $3 \mathrm{~kg}$, she underwent an interventional PDA closure in a referring institution.

In the last few months the parents observed increasing symptoms of heart failure - shortness of breath, anxiety, lack of appetite, and fatigability that began just after the intervention. Although the symptoms were persistently reported to the cardiologists by the parents, echocardiographic controls showed a constantly good effect of interventional PDA closure, without any reasonable suspicion of interrupted aortic blood flow.

Transthoracic echocardiography (TTE) performed on admission showed myocardial injury, with poor contractility and severe valvular incompetence, mild pulmonary hypertension and severe stenosis of the isthmus of the aorta. Further precise TTE showed the critical aortic stenosis of the aorta caused by the aortic disc of the occluder that was used for PDA closure (Photo 1). Chest X-ray on admission showed

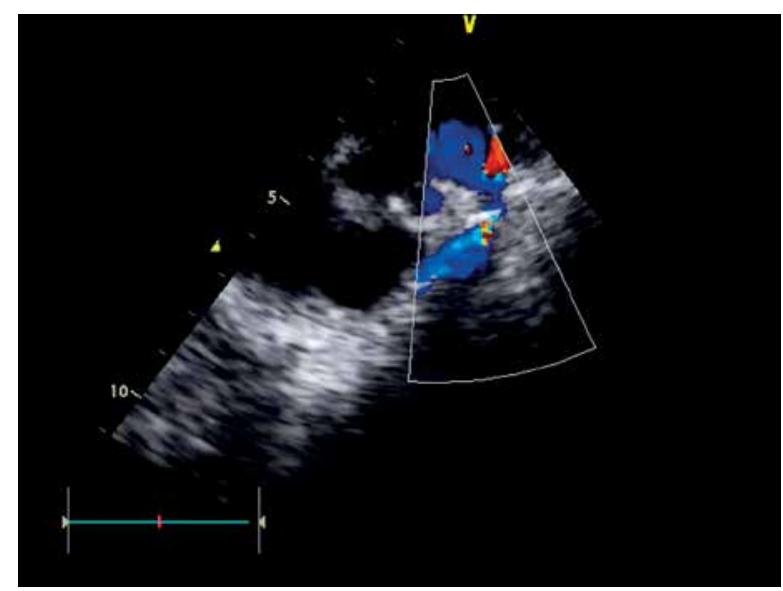

Photo 1. Echocardiography (TTE) performed on admission: severe 'coarctation' of the aorta caused by the aortic disc of the occluder, which was implanted to close the PDA a severely enlarged heart silhouette with cardiac index $=0.8$ (Photo 2).

The girl was urgently referred for surgical removal of the occluding device. The procedure with extracorporeal circulation (ECC) and deep hypothermia circulatory arrest (DHCA) technique was performed. Intraoperatively there was significant pericardial effusion, and generally impaired contractility of the heart, with enlarged chambers, observed especially in the left ventricle (LV) wall motion. There was a macroscopic inflammatory-type reaction seen in the soft tissues surrounding the PDA, as well as changes in the arterial wall of both sides of the PDA: pulmonary and aortic. The double-disc occluder was removed with a margin of aortic and pulmonary artery walls. The reconstruction of the aorta and pulmonary artery was performed using a bovine xenograft (Contegra EU) patch.

Her early postoperative period was uneventful. Severe arterial hypertension with a good response to pharmacological treatment was initially observed. Catecholamine infusion was gradually reduced, with satisfactory circulatory compensation. In postoperative TTE there was impaired heart function (ejection fraction of the left ventricle increased from $21 \%$ to $35 \%$ ), with unobstructed aortic blood flow. The girl was discharged to an initial reference pediatric cardiology center in improved general condition, without pharmacological cardiovascular support, with the features of early recovery.

She was readmitted after a couple of hours again to the Intensive Care Unit because of cardiovascular

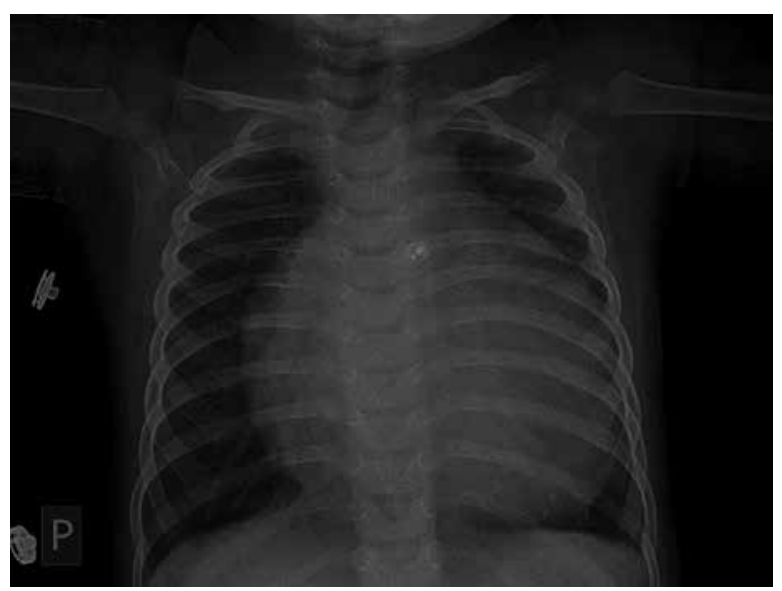

Photo 2. Chest X-ray on admission. Cardiac index 0.8. Note the irregular shape of the PDA-occluding device in the area of the aortic arch 
decompensation. Intensive pharmacological treatment was ineffective because of severe heart failure. The child died after seven days due to circulatory arrest in the mechanism of refractory ventricular fibrillation.

In the autopsy there were found microscopic signs of apoptosis in parenchymal organs below the iatrogenic 'coarctation', typical for chronic ischemia. The hypothesis was that fatal consequences of apoptosis were probably initiated by oxidative stress caused by reperfusion, after aortic repair. Moreover, in the segments proximal to iatrogenic aortic stenosis there were evident vascular changes characteristic for chronic severe arterial hypertension.

\section{Discussion}

Nowadays transcatheter closure of the PDA using either coils or plugs is a well-established procedure of choice in children, except neonates and young infants. Therefore interventional PDA closure became a first-line procedure considered in the treatment of every isolated patent arterial duct, which limited the need for classic or miniinvasive surgical ligation [4]. Presently in our institution surgery for PDA ligation is available only for premature newborns, or complex, borderline, or highly complicated cases. Single-center reported series and multicenter trials, as well as various registries, include a wide range of sizes and patients at different ages. This frequently mentioned common practice was facilitated by wide access to a variety of devices, coils, and assigned implantation techniques [1].

The technical aspects were precisely described as well as relevant professional recommendations with regard to individual selection of patients. On the other hand, there is a lack of universal criteria to postpone, or even abandon the interventional treatment in suboptimal patients, or troublesome clinical circumstances. In every difficult situation the definitive strategy still remains surgical ligation, in a classic manner performed with PDA division [5]. Nonetheless, surgery is unwillingly considered only after previously attempted, or failed PDA intervention. Operative treatment, despite established surgical techniques, sometimes does not provide a complete PDA closure, and the 'recanalization' phenomenon is observed after both surgery and intervention [6].

Embolizations and malpositions are the most dangerous complications recorded and classified according to attributability and severity considered in the CHARM adverse events (AE) stratification scale (Table I) [7]. Embolization was defined as a released coil or device that was no longer located in the PDA. Malposition was defined as a coil or devices that were released and then had to be retrieved due to having an abnormal position within the PDA.

Nevertheless, there are still some presently observed 'gray' areas that include the results of PDA interventions in the group of 'borderline' patients. In our opinion, some special consideration is needed for small babies referred for percutaneous treatment with hardly fulfilled, or off-label device implantations - with regard to technical recommendations. Following the literature data, there is an unquestionable tendency to apply percutaneous therapies to smaller and younger patients. Thus in many reports patients younger than 6 months and weighing less than $6 \mathrm{~kg}$ are indicated as the group in which complications related to percutaneous PDA closure still appear most frequently.

According to multicenter analysis presented by El-Said et al., who presented a group of 496 interventional PDA-closure patients, the adverse event (AE) rate was 7\% (46 cases) [8]. After meticulous analysis of presented data, the authors stated that the $A E$ rate was higher among children weighing $<6 \mathrm{~kg}$, with a rate of any event of $27 \%$ versus general $8 \%(p=0.002)$ and high-severity events of $10 \%$ vs. general $2 \%$ [7]. In the total of 46 adverse events, 24 were embolizations and malpositions (5\%). Accordingly, in a univariate analysis, AEs were more likely to occur in young patients $<6$ months and in patients $<6 \mathrm{~kg}$.

There is an impression that universally approved classification of early AEs should be modified in the light of currently presented reports of postponed embolizations, because of delayed malpositions of implants, which could result in fatal consequences. Our patient presented in the above report is an excellent example, so we had some real difficulties with proper qualification of her problems in accordance with available stratification scales [7]. The phenomenon of protrusion of an aortic disc PDA-occluding device is well known $[9,10]$, although still not classified, and should always be taken into consideration during outpatient follow-ups.

Patients weighing below $6 \mathrm{~kg}$ should undergo some particularly careful control protocols because of some possible, and sometimes even predictable, procedure-related complications assigned to their interventional treatment. Probably this was the ar- 
Table I. Definition of adverse events' severity - reprinted from [7]

\begin{tabular}{|c|c|c|c|}
\hline $\mathrm{AE}$ & $\begin{array}{l}\text { Severity } \\
\text { level }\end{array}$ & Definition & Examples \\
\hline \multirow[t]{2}{*}{ Low } & $\begin{array}{c}1 \text { - None } \\
\text { (very mild) }\end{array}$ & $\begin{array}{l}\text { No harm, no change in condition, may have required } \\
\text { monitoring to assess for potential change in condi- } \\
\text { tion with no intervention indicated }\end{array}$ & $\begin{array}{l}\text { Imaging equipment problem, medication error, } \\
\text { minor bleeding from access site without hemato- } \\
\text { ma resolved with compression, device malfunc- } \\
\text { tion removed easily, short self-limited arrhythmia } \\
\text { from catheter manipulation }\end{array}$ \\
\hline & 2-Minor & $\begin{array}{l}\text { Transient change in condition, not life threatening, } \\
\text { condition returns to baseline, required monitoring, } \\
\text { required minor intervention such as holding a medi- } \\
\text { cation, or obtaining a lab test }\end{array}$ & $\begin{array}{l}\text { Coil malposition or embolization while in the } \\
\text { cath lab easily retrieved, device malposition } \\
\text { requiring sheath size change or snaring, pulse } \\
\text { loss resolved spontaneously, hematoma or large } \\
\text { bruising, minor airway problem, transient ar- } \\
\text { rhythmia, allergic reaction }\end{array}$ \\
\hline \multirow[t]{3}{*}{ High } & 3-Moderate & $\begin{array}{l}\text { Transient change in condition may be life threat- } \\
\text { ening if not treated, condition returns to baseline, } \\
\text { required monitoring, required intervention such as } \\
\text { reversal agent, additional medication, transfer to the } \\
\text { intensive care unit for monitoring, or moderate tran- } \\
\text { scatheter intervention to correct condition }\end{array}$ & $\begin{array}{l}\text { Blood loss, hemothorax, respiratory acidosis, } \\
\text { atrial arrhythmia requiring intervention, anes- } \\
\text { thesia problem requiring reintubation, any de- } \\
\text { vice embolization in the catheterization lab or } \\
\text { afterward }\end{array}$ \\
\hline & 4-Major & $\begin{array}{l}\text { Change in condition, life threatening if not treated, } \\
\text { change in condition may be permanent, may have } \\
\text { required an intensive care unit admission or emer- } \\
\text { gent readmit to hospital, may have required invasive } \\
\text { monitoring, required interventions such as electri- } \\
\text { cal cardioversion or unanticipated intubation or re- } \\
\text { quired major invasive procedures or transcatheter } \\
\text { interventions to correct condition }\end{array}$ & $\begin{array}{l}\text { Ventricular arrhythmia requiring medication, } \\
\text { vessel dissection, hypotension requiring inotrope } \\
\text { support, atrioventricular block, coil or device mal- } \\
\text { position or embolization requiring surgery }\end{array}$ \\
\hline & $\begin{array}{c}5 \text { - Catastro- } \\
\text { phic }\end{array}$ & $\begin{array}{l}\text { Any death, and emergent surgery or heart lung by- } \\
\text { pass support (ECMO) to prevent death with failure } \\
\text { to wean from bypass support }\end{array}$ & Death \\
\hline
\end{tabular}

$A E$ - adverse events, $A V$ - atrioventricular, ECMO - extracorporeal membrane oxygenation.

gument for very strict manufacturer's recommendations that preclude the use of their products (coils and occluding devices) in patients younger than 6 months weighing less than $6 \mathrm{~kg}$.

In our opinion, the lack of systemic specialist outpatient controls was a reason for the undetected complication in the form of aortic obstruction, and its fatal final result. Surgical removal of the implant with aortic arch repair was a dramatic attempt to save the life of the child, who suffered chronically from oversight implant migration. The surgery was undertaken in an emergency setting with severe congestive heart failure caused by covered iatrogenic aortic 'coarctation', probably caused by the initially oversized, and then displaced implant. The symptoms of low cardiac output, severe hypertension arterial changes over aortic stenosis with the evidence of apoptosis below the aortic 'coarctation' prove the hypothesis of a long-lasting process, and clearly explain the irreversible multiorgan injury that caused the fatal result of surgical repair.

Finally it is our responsibility to refer our patients for optimally designed cardiovascular procedures, as well as to monitor the results, not only in immediate observation. Thus the idea of a 'heart team' that results in close cooperation between specialists to provide maximal benefits for borderline patients should be emphasized.

\section{Conclusions}

Qualification for intervention should be made by a competent heart team with consideration of the current clinical condition of the patient, and basically the anatomic parameters (body weight, size of the vessels, and age) to respect the manufacturer's technical recommendations.

Post-interventional echocardiographic controls should be an integral part of interventional treat- 
ment protocols, which is twice as important in every case of percutaneous devices used 'off label'.

Professional, precise and regularly scheduled outpatient controls run by an honest pediatric cardiologist could prevent the occurrence of overlooked complications, and initiate the appropriate treatment before the progression of fatal consequences.

\section{Acknowledgments}

Special thanks to our colleagues, who made an important contribution in preparation of the manuscript: Mariusz Steffens, Aneta Szofer-Sendrowska, Anna Romanowicz, Ewelina Kwaśniak, Katarzyna Gierat-Haponiuk.

\section{Conflict of interest}

The authors declare no conflict of interest.

\section{References}

1. Tometzki AJ, Arnold R, Peart I, et al. Transcatheter occlusion of the patent ductus arteriosus with Cook detachable coils. Heart 1996; 76: 531-4.

2. Faella HJ, Hijazi ZM. Closure of the patent ductus arteriosus with the Amplatzer PDA device: immediate results of the international clinical trial. Catheter Cardiovasc Interv 2000; 51: 50-4.

3. Porstmann W, Wierny L, Warnke H, et al. Catheter closure of patent ductus arteriosus: 62 cases treated without thoracotomy. Radiol Clin North Am 1971; 9: 203-18.

4. Stankowski T, Aboul-Hassan SS, Marczak J, et al. Is thoracoscopic patent ductus arteriosus closure superior to conventional surgery? Interact Cardiovasc Thorac Surg 2015; 21: 532-8.

5. Mavroudis C, Backer CL, Gevitz M. Forty-six years of patent duCtus arteriosus division at Children's Memorial Hospital of Chicago: standards for comparison. Ann Surg 1994; 220: 402-10.

6. Białkowski J, Szkutnik M, Kusa J, et al. Przezskórne zamykanie rekanalizowanych przewodów tętniczych. Kardiol Pol 2007; 65: 125-9.

7. Bergersen L, Gauvreau K, Foerster SR, et al. Catheterization for congenital heart disease adjustment for risk method (CHARM). JACC Cardiovasc Interv 2011; 4: 1037-46.

8. El-Said HG, Bratincsak A, Foerster SR, et al. Safety of percutaneous patent ductus arteriosus closure: an unselected multicenter population experience. I Am Heart Assoc 2013; 2: e000424.

9. Dryżek P, Michalak K, Moszura T, et al. Late coarctation of aorta caused by protrusion of Amplatzer duct occluder - a case report of transcatheter treatment. Postep Kardiol Inter 2010; 6: 134-7.

10. Masri S, El Rassi I, Arabi M, et al. Percutaneous closure of patent ductus arteriosus in children using amplatzer duct occluder II: relationship between PDA type and risk of device protrusion into the descending aorta. Catheter Cardiovasc Interv 2015; 86: E66-72.

Received: 27.11.2015, accepted: 29.12.2015. 